\title{
Analysis of Excessive Day Time Sleepiness in Adolescent Girls Pursuing Professional Courses
}

\section{Ravi Sunder $\mathbf{R}^{\mathbf{1}}$ and Neelima $\mathbf{P}^{2 *}$}

${ }^{1}$ Professor and HOD, Physiology, GIMSR, GITAM Deemed to be University,

Visakhapatnam, Andhra Pradesh, India

${ }^{2}$ Professor and HOD, Anatomy, NRIIMS, Dr. NTRUHS, Visakhapatnam, Andhra

Pradesh, India

*Corresponding Author: Neelima P, Professor and HOD, Anatomy, NRIIMS, Dr. NTRUHS, Visakhapatnam, Andhra Pradesh, India.
Received: November 24, 2021

Published: January 21, 2022

(C) All rights are reserved by Ravi Sunder $\mathbf{R}$ and Neelima $\mathbf{P}$.

\begin{abstract}
Excessive daytime sleepiness may range from drowsiness to uncontrollable diurnal sleep attacks called narcolepsy. Though many causes can be attributed to day time sleepiness, most common physiological reason could be late night interrupted sleep. With the advent of smartphones and gaming hobbies adolescents become the vulnerable age group to be victimized for the day time sleepiness. Literature is scanty on the assessment of sleepiness score from north coastal Andhra Pradesh. This study has been done to evaluate the sleepiness in medical and dental girl students from north coastal Andhra Pradesh. Epworth sleepiness score has been used as a tool to assess the person's average sleep propensity. It consists of eight questions and the score is interpreted basing on the individual's response. The aim of study has been explained to the participants. After taking informed consent,164 girl students from $1^{\text {st }}$ year medical and dental courses with age between 17-20 years, participated in the study. Identity was kept anonymous and the score calculated. 2 girls got a maximum score of 19 which was interpreted as severe excessive daytime sleepiness using Epworth Sleepiness Score. The minimum score obtained from the study was 2 points given by 2 girls. This is named as lower normal daytime sleepiness. The study group was addressed after analyzing the results. Most of the students admitted that they sleep late in the night and the main culprit disturbing their sleep was the smartphone. They were advised to follow healthy sleep patterns for a wholesome healthy life and also to retain memory and increase attention span to achieve academic excellence. The present study reflects the average sleep propensity of the adolescent girl students of north coastal Andhra Pradesh.
\end{abstract}

Keywords: Sleepiness Score; Daytime Sleepiness; Adolescent Girl Students; Medical; Dental Students

\section{Introduction}

For the brain to actively function, one should have a normal sleep for about 7-9 hours. Our brain remains active during sleep, formatting all the information gathered just like the smart phone or laptop. Sleep deprivation causes adverse effects both physically and mentally. Carskadon., et al. [1] described the importance of normal sleep in memory consolidation and cellular growth. Lack of proper sleep may lead to day time sleepiness where a person would not be expected to sleep. According to Dhand., et al. [2] ex- cessive daytime sleepiness disrupts learning process and overall health of the individual. Partinen [3] defined excessive daytime sleepiness as a condition, when a person is expected to be awake, increasingly falls asleep associated with tiredness and loss of mental alertness. This may be observed along with some medical illness like asthma, renal failure or gastroesophageal reflux disease.

The risk of excessive daytime sleepiness is more in persons with insomnia as mentioned by Kao., et al. [4]. Routine early bed time sleep practice helps to overcome daytime sleepiness. If left unad- 
dressed, excessive day time sleepiness may lead to long term complications. Panossian., et al. [5] stated the reduced quality of life as a deleterious effect of excessive daytime sleepiness. The academic performance of a student in a professional course is determined by the active brain status which in turn depends on the healthy sleeping habits of the individual. Late night or interrupted sleep patterns may lead to sleep disturbances causing day time sleepiness. The student remains inattentive academically during daytime resulting in poor performance. The present study has been undertaken to assess the daytime sleepiness among girls pursuing $1^{\text {st }}$ year medical and dental sciences from north coastal Andhra Pradesh.

\section{Materials and Methods}

The aim of the study was explained to the medical and dental students. The research design is a cross-sectional study and the research method used was questionnaire based. The study sample included only girls who are adolescents with age ranging between 17-20years, as the study was intended for them. After taking informed consent, Epworth sleepiness scale with 8 questions was circulated by google forms. 164 girls took part in the study. They were asked to fill the appropriate option. Keeping identity anonymous, the reports were analysed and graphically represented.

\section{Results}

The following results were obtained from the study.

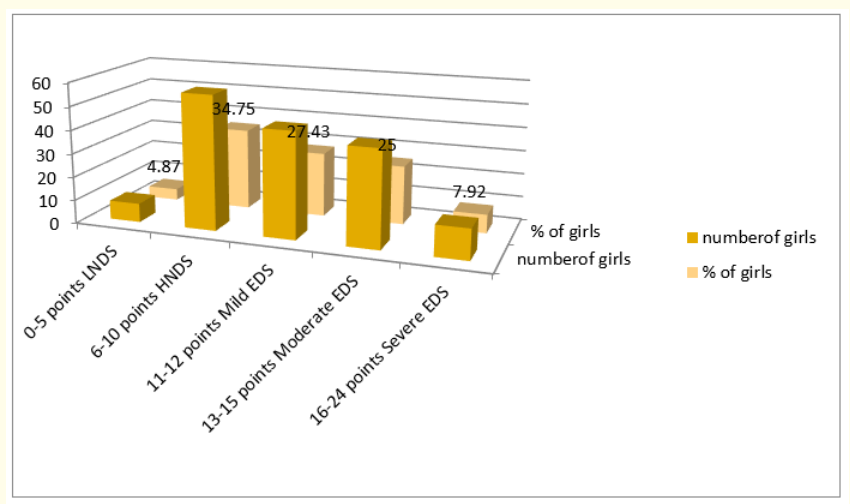

Graph 1: Showing scores achieved by number of girls and percentage.

LNDS: low normal daytime sleepiness

HNDS : High normal daytime sleepiness

EDS: Excessive daytime sleepiness.

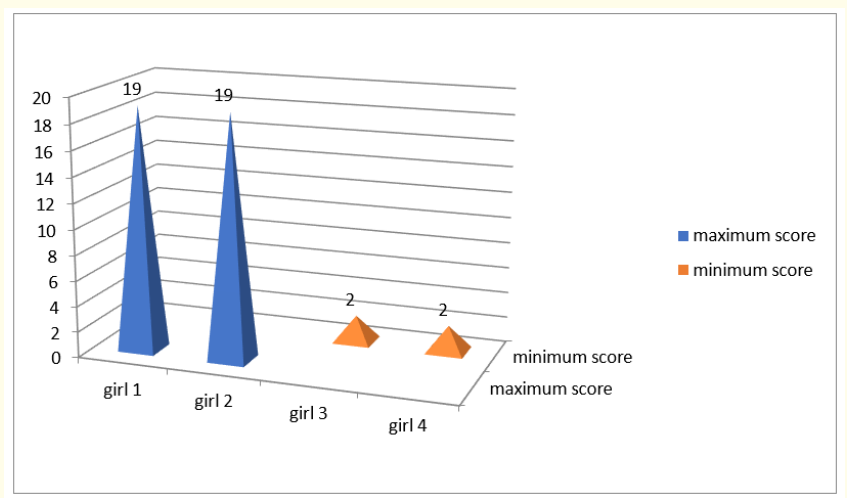

Graph 2: Illustrating maximum and minimum scores from the study.

$34.75 \%$ students report high normal daytime sleepiness. Maximum score from the study is 19 which falls in the range of 16-24 of Epworth sleepiness scale and is interpreted as excessive day time sleepiness.

Minimum score is 2, seen in the range of 0-7 and this corresponds to low normal daytime sleepiness.

\section{Discussion}

Healthy sleep plays a vital role in physical and mental well being of an individual. Good sleep habits and perfect sleep routine makes a person to think wise and stay strong. Sleep deprivation, due to consistent lack of sleep or reduced sleep quality may lead to daytime sleepiness affecting the physical and mental health. Students in particular, adolescents pursuing professional courses, should have a sound sleep with good sleeping habits and routine. This reflects on their academic abilities. Dagnew., et al. [6] reported high prevalence of excessive daytime sleepiness in medical students adversely affecting their academic performance. Rose., et al. [7] correlated the association of depression in excessive daytime sleepiness. Hormonal alterations have also been observed due to excessive daytime sleepiness. Muhlen., et al. [8] illustrated the role of cortisol on hippocampus causing depression in day time sleepiness. Alsaggaf., et al. [9] stated that excessive daytime sleepiness is associated with stress. Psychological effects of excessive daytime sleepiness have been postulated by Mume., et al. [10] in their study. By this it is understood that a healthy sleep of 7-9 hours is essential to get rid of daytime sleepiness. The present study has been done to 
detect and analyse the excessive daytime sleepiness in adolescent girls pursuing their $1^{\text {st }}$ year in medical and dental sciences. $34.75 \%$ students reported high normal daytime sleepiness. This is in accordance with study by El Hangouche., et al. [11]. 2 students exhibited excessive daytime sleepiness with score 19. From the present study, it can be analysed that most of the students reveal high normal to mild excessive day time sleepiness. It is very important at this stage to prevent further progress towards excessive daytime sleepiness. The study group was addressed after the results were analysed and were cautioned about the deleterious effects of daytime sleepiness. They were adviced to follow healthy sleep routine and to get rid of unwanted habits that interrupt their sleep which reflect on their physical and mental well being.

\section{Conclusion}

High normal daytime sleepiness was reported in maximum number of girl students. A considerable percentage revealed mild to moderate excessive daytime sleepiness.

\section{Bibliography}

1. Carskadon MA and Dement WC. "Normal human sleep: an overview". Principles and Practice of Sleep Medicine 4 (2005): 13-23.

2. Dhand R and Sohal H. "Good sleep, bad sleep! The role of daytime naps in healthy adults". Current Opinion in Pulmonary Medicine 12.6 (2006): 379-382.

3. Partinen M. "Epidemiology of sleep disorders". Handbook of Clinical Neurology 98 (2011): 275-314.

4. Kao CC., et al. "Insomnia: prevalence and its impact on excessive daytime sleepiness and psychological well-being in the adult Taiwanese population". Quality of Life Research 17.8 (2008): 1073-1080.

5. Panossian LA and Veasey SC. "Daytime sleepiness in obesity: mechanisms beyond obstructive sleep apnea--a review". Sleep 35.5 (2012): 605-615.

6. Dagnew B., et al. "Excessive daytime sleepiness and its predictors among medical and health science students of University of Gondar, Northwest Ethiopia: institution-based cross-sectional study". Health Qual Life Outcomes 18.1 (2020): 299.

7. Rose D., et al. "Morningness/eveningness chronotype, poor sleep quality, and daytime sleepiness in relation to common mental disorders among Peruvian college students". Psychology, Health and Medicine 20.3 (2015): 345-352.
8. Mühlen K aus der and Ockenfels H. "Morphological alterations in the diencephalon and telencephalon following disturbances to the feedback mechanism adenohypophysis-adrenal cortex. 3. Studies on the guinea pig after administration of cortisone and hydrocortisone]". Z Zellforsch Mikrosk Anat 93.1 (1969): 126-141.

9. Alsaggaf MA., et al. "Sleep quantity, quality, and insomnia symptoms of medical students during clinical years. Relationship with stress and academic performance". Saudi Medical Journal 37.2 (2016): 173-182.

10. Mume CO., et al. "Excessive daytime sleepiness, nocturnal sleep duration and psychopathology among Nigerian university students". South African Journal of Psychiatry 17.4 (2011): 108-111.

11. El Hangouche AJ., et al. "Relationship between poor quality sleep, excessive daytime sleepiness and low academic performance in medical students". Advances in Medical Education and Practice 9 (2018): 631-638.

\section{Assets from publication with us}

- Prompt Acknowledgement after receiving the article

- Thorough Double blinded peer review

- Rapid Publication

- Issue of Publication Certificate

- High visibility of your Published work

Website: www.actascientific.com/

Submit Article: www.actascientific.com/submission.php Email us: editor@actascientific.com

Contact us: +919182824667 